\title{
Fakor-Faktor Yang Mempengaruhi Pendapatan Petani Padi Di Kelurahan Pekkabata Kecamatan Duampanua Kabupaten Pinrang
}

\author{
Factors Affecting the Income of Rice Farmers in Pekkabata Village, Duampanua District, \\ Pinrang Regency \\ Muhammad Idrus $^{1 *}$, Nurhapsa ${ }^{1}$, Yusriadi ${ }^{1}$ \\ *Email: idrus9144@gmail.com \\ ${ }^{1}$ Fakultas Pertanian, Peternakan dan Perikanan Universitas Muhammadiyah Parepare \\ Diterima: 11 September 2021 / Disetujui: 20 Desember 2021
}

\begin{abstract}
ABSTRAK
Penelitian ini bertujuan untuk mengetahui Apakah faktor luas lahan, jumlah tenaga kerja ,biaya produkisi dan bibit berpengaruh terhadap pendapatan petani padi di Kecamatan Duampanua Kelurahan Pekkabata dan Untuk mengetahui faktor apa yang paling berpengaruh diantara luas lahan, jumlah tenaga kerja, biaya produkisi dan bibit terhadap pendapatan petani padi di Kelurahan Pekkabata Kecamatan Duampanua Kabupaten Pinrang. Data yang digunakan dalam penelitian ini adalah data primer dan sekunder. Metode anilisis data yang digunakan adalah metode deskriptif dan metode regresi linear berganda. Hasil penelitian menunjukkan bahwa variabel luas lahan jumlah tenaga kerja, biaya produksi memiliki pengaruh yang signifikan terhadap pendapatan petani padi di Kecamatan Duampanua Kelurahan Pekkabata.
\end{abstract}

Kata Kunci: Luas Lahan, Jumlah Tenaga Kerja, Biaya Produksi, Bibit Dan Pendapatan, Usahatani Padi, Regresi Linear Berganda.

\begin{abstract}
This study aims to find out whether the factors of land area, number of workers, production costs and seeds affect the income of rice farmers in Duampanua District, Pekkabata Village and to find out what factors are the most influential among land area, number of workers, production costs and seeds on the income of rice farmers in Pekkabata Village, Duampanua District, Pinrang Regency. The data used in this study are primary and secondary data. The data analysis method used is descriptive method and multiple linear regression method. The results showed that the variables of land area, number of workers, production costs had a significant influence on the income of rice farmers in Duampanua District, Pekkabata Village.
\end{abstract}

Keywords: Land Area, Number Of Workers, Production Costs, Seeds, And Income, Rice Farming, Multiple Linear Regression.

(c) ()

\section{A. PENDAHULUAN}

Wilayah Kabupaten Pinrang

Kecamatan Duampanua Kelurahan

Pekkabata petani padi bisa menikmati dua

kali panen selama satu tahun. Namun

Petani padi seringkali menemukan

permasalahan-permasalahan dalam usaha taninya. Permasalahan tersebut dimulai dari proses pembibitan sampai pada proses pemanenan itu selalu ada hambatan seperti serangan hama, harga padi yang tidak tetap, mahalnya biaya sewa alat pengolahan lahan dan juga cuaca yang sulit diprediksi. itu semua yang membuat petani 
terkadang tidak mendapatkan hasil panen yang maksimal. Salah satu Kelurahan di Kabupaten Pinrang yang perekonomiannya bertumpu pada sektor pertanian adalah Di Kabupaten Pinrang, Kecamatan Duampanua Kelurahan Pekkabata. Hingga saat ini, Kelurahan Pekkabata mampu memproduksi padi ratarata 8,2 Ton. Permasalahan lain yang ada pada usaha tani padi yaitu harga padi yang tidak stabil.
Kecamatan Duampanua adalah kecamatan yang terletak di Kabupaten Pinrang, Sulawesi Selatan. Kecamatan Duampanua memiliki luas wilayah 29.186 Ha yang terdiri dari lahan sawah 7.247,00 Ha, lahan kering 17.586,96 Ha dan lahan basah 4.352,04 Ha,(Badan Pusat Statistik Kabupaten Pinrang, 2017).

Adapun jenis tanaman, luas panen, jumlah produksi di Kecamatan Duampanua sebagaimana tabel dibawah sebagai berikut.

Tabel 1. Jenis Tanaman Tanaman, Luas Panen, Jumlah Produksi Di Kecamatan Duampanua

\begin{tabular}{clcc}
\hline No & Jenis Tanaman & uas Panen ( Ha ) & Produksi ( Ton ) \\
\hline 1 & Padi Sawah & 14.599 & 85.959 \\
2 & Jagung & 3.523 & 23.382 \\
3 & Ubi jalar & 10 & 161 \\
4 & Kacang tanah & 7 & 14 \\
5 & Kacang Hijau & 10 & 13 \\
6 & Wortel & 21 & 266,9 \\
7 & Kacang panjang & 16 & 193,7 \\
8 & Cabe & 8 & 74,1 \\
9 & Terong & 18 & 213,9 \\
10 & Kangkung & 16 & 177,3 \\
11 & Bayang & 14 & 72,5 \\
12 & Ketimun & 14 & 244,9 \\
\hline
\end{tabular}

Sumber:Badan Pusat Statistik Kabupaten Pinrang 2017 
Berdasarkan tabel 1. padi merupakan tanaman paling banyak di produksi dengan luas lahan panen 14.599 Ha di Kecamatan Duampanua. Ini yang membuat kebanyakan masyarakat pada bidang Ekonominya lebih cenderung memilih menjadi petani padi.

Permasalahannya adalah tidak menentunya pendapatan petani padi di Kelurahan pekkabata dalam setiap panennya. Oleh karena itu sangat penting untuk bisa mengetahui bagaimana pengaruh faktor luas lahan, jumlah tenaga kerja, biaya produkisi dan bibit terhadap pendapatan petani padi tersebut.

Dari uraian di atas maka penulis tertarik untuk melakukan penelitian dengan mengangkat judul "Faktor- Faktor Yang Mempengaruhi Pendapatan Petani Di Kelurahan Pekkabata, Kecamatan Duampanua, Kabupaten Pinrang”.

Adapun tujuan dari penelitian ini adalah Untuk mengetahui pengaruh faktor luas lahan, jumlah tenaga kerja ,biaya produkisi dan bibit terhadap pendapatan petani padi di Kecamatan Duampanua Kelurahan Pekkabata dan Untuk mengetahui Faktor yang paling berpengaruh diantara luas lahan, jumlah tenaga kerja, biaya produkisi dan bibit terhadap pendapatan petani padi di Kecamatan Duampanua Kelurahan Pekkabata.

\section{B. METODE PENELITIAN}

\section{Tempat dan waktu}

Penelitian ini dilaksanakan pada bulan November 2019 sampai bulan Maret 2020 yang berlokasi di Kelurahan Pekkabata Kecamatan Duampanua Kabupaten Pinrang. Alasan peneliti memilih lokasi tersebut karena peneliti melihat potensi tanaman Padi Di Kelurahan Pekkabata sehingga peneliti ingin mengetahui apa saja faktor yang mempengaruhi pendapatan petani di Kelurahan Pekkabata Kecamatan Duampanua Kabupaten Pinrang.

\section{Populasi dan Sampel}

Populasi yaitu keseluruhan dari objek penelitian.Populasi yang diambil oleh peneliti dalam penelitian ini yaitu petani padi di Kelurahan Pekkabata Kecamatan Duampanua Kabupaten Pinrang sebanyak 412 petani padi. Sampel yaitu sebagian dari jumlah populasi yang akan diteliti. Dengan melihat waktu, tenaga, luas wilayah penelitian dan dana sehingga penulis dalam menentukan jumlah sampel dengan menggunakan metode simple random sampling. Metode simple random sampling merupakan pengambilan sampel secara acak.Kasmadi dan Sunariah (2013) berpendapat bahwa 
"teknik simple random sampling", yaitu teknik sampling sederhana yang dilakukan secara acak tanpa memperhatikan strata yang diungkapkan W.Gulo (2005) yaitu "bahwa setiap anggota populasi mempunyai peluang yang sama untuk ditarik sebagai anggota sampel”. Mengacu pada pedoman Arikunto (dalam Kasmadi dan Sunariah, 2013) apabila subyek populasi lebih dari 100, maka sampel dapat diambil antara $10 \%$ sampai $25 \%$. Populasi pada penelitian ini sebanyak 412 orang petani dan sampel yang saya ambil sebanyak 41 orang petani padi.

\section{Jenis dan Sumber Data}

Jenis data yang digunakan dalam penelitian ini terbagi menjadi dua berdasarkan pada pengelompokannya yaitu:

a. Data primer adalah data yang dikumpulkan dari sumber data pertama (Soekartawi, 2002). Data primer diperoleh melalui survei lapanagn dan wawancara terhadap para petani di Kelurahan Pekkabata Kecamatan Duampanua Kabupaten Pinrang. Adapun data primer yang dikumpulkan adalah 41 Responden. b. Data sekunder adalah data yang dikumpulkan dari sumber ke-2 (Soekartawi, 2002). Data sekunder diperoleh melalui studi kasus pustaka yaitu dengan membaca buku-buku yang berkaitan dengan penelitian yang dilakukan, serta dari penelitianpenelitian sebelumnya. Data sekunder juga diperoleh dari BPS (Badan Pusat Statistik) Kabupaten Pinrang.

\section{Teknik Pengumpulan Data}

Data yang diperoleh dalam penelitian ini yaitu dilakukan dengan teknik sebagai berikut :

a. Interview yaitu teknik dengan sebuah dialog yang dilakukan oleh pewawancara (interviewer) untuk memperoleh informasi dari narasumber, yaitu orang yang diwawancarai.

b. Observasi yaitu teknik yang digunakan sebagai pelengkap data dan untuk melihat serta mencermati secara langsung tempat yang akan diteliti.

c. Dokumentasi yaitu salah satu teknik yang melihat dokumen-dokumen dan laporan-laporan yang mempunyai hubungan dengan yang ingin diteliti.

d. Koesioner terbuka yaitu pertanyaan yang memberi pilihan-pilihan respon terbuka kepada responden.

\section{Teknik Analisis Data}


a. Metode deskriptif yaitu analisis yang digunakan untuk mengungkapkan atau menggambarkan sesuatu mengenai keadaan yang sesuai dengan fakta dan yang akurat dari tempat yang diteliti. Dan sesuai dengan teori yang berlaku serta diakui. Metode ini digunkan untuk menerangkan identitas responden, dan Teknik ini juga digunakan untuk mencari solusi dari masalah yang terjadi terkait dengan faktor-faktor yang mempengaruhi pendapatan petani padi di Kelurahan Pekkabata Kecamatan Duampanua Kabupaten Pinrang.

b. Untuk mengetahui faktor-faktor yang berpengaruh nyata pada pendapatan petani padi maka digunakan model Analisis Regresi Berganda dengan model kuadran terkecil (Ordinary Least Square/OLS). Analisis ini digunakan untuk mengetahui faktorfaktor yang mempengaruhi pendapatan usahatani adalah analisis regresi berganda yang secara matematis dapat dirumusan dengan menggunakan pendekatan statistik kemudian dilinearkan dengan menggunkan logaritma natural (In) maka membentuk persamaan sebagai berikut :

$$
\mathrm{Y}=\alpha+\mathrm{X}_{1}+\mathrm{X}_{2}+\mathrm{X}_{3}+\mathrm{X}_{4}+\mathrm{e}
$$

Dimana :

Y : Pendapatan Petani Padi (Rp)

$\alpha \quad$ : Konstanta

$\mathrm{X}_{1}$ : Luas Lahan ( Ha )

$\mathrm{X}_{2}$ : Jumlah Tenaga Kerja (Orang)

$\mathrm{X}_{3}$ : Biaya Produksi ( $\mathrm{Rp}$ )

$\mathrm{X}_{4}$ : Bibit (bersertifikat dan tidak bersertfikat)

e : Standar Error

\section{HASIL DAN PEMBAHASAN}

1. Hasil Analisis yang Mempengaruhi Pendapatan Petani Padi di Kelurahan Pekkabata Kecamatan

\section{Duampanua Kabupaten Pinrang}

Berdasarkan rumusan masalah yang diuraikan pada latar belakang adalah bagi nilai dimana luas lahan ,jumlah tenaga kerja dan biaya produksi terhadap pendapatan petani padi di Kelurahan Pekkabata Kecamatan Duampanua Kabupaten Pinrang dan untuk mengetahui apakah ada pengaruh yang signifikan antara variabel dependen dan variabel independen ( $\mathrm{X}$ ) yaitu $\mathrm{X}_{1}$ ( Luas lahan), $\mathrm{X}_{2}$ ( Jumlah Tenaga Kerja), $\mathrm{X}_{3}$ (Biaya Produksi) dan $\mathrm{X}_{4}$ (Bibit) serta variabel dependen Y ( Pendapatan ) Petani padi ini merupakan hasil penelitian yang telah di dapatkan dilapangan. 
Penelitian ini dilakukan dengan dan utnuk mengetahui faktor-faktor yang menggunakan alat ukur skala metode berpengaruh nyata terhadap pendapatan analisis deskripsi linear berganda dengan membagikan kuesioner kepada responden yang terkait dengan jumlah 41 responden petani padi tersebut dapat dilihat pada tabel program alat anlisis (SPSS) regresi Linear Berganda di bawah ini.

Tabel 2. Coefficients Faktor Yang Mempengaruhi Pendapatan Petani Padi Di Kelurahan Pekkabata Kecamatan Duampanua Kabupaten Pinrang

\begin{tabular}{|c|c|c|c|c|c|c|}
\hline \multicolumn{7}{|c|}{ Coefficients $^{\mathbf{a}}$} \\
\hline \multirow{2}{*}{\multicolumn{2}{|c|}{ Model }} & \multicolumn{2}{|c|}{ Unstandardized Coefficients } & \multirow{2}{*}{$\begin{array}{l}\text { Standardized } \\
\text { Coefficients } \\
\text { Beta }\end{array}$} & \multirow[t]{2}{*}{$\mathrm{t}$} & \multirow[t]{2}{*}{ Sig. } \\
\hline & & B & Std. Error & & & \\
\hline \multirow{5}{*}{1} & (Constant) & 303717.802 & 3281855.898 & & .093 & .927 \\
\hline & Luas Lahan & 265426.632 & 27603.140 & 1.064 & 9.616 & 000 \\
\hline & Jumlah Tenaga Kerja & -108609.592 & 376678.977 & -.021 & -.288 & ,775 \\
\hline & Biaya Produksi & -1.423 & .835 & -.182 & -1.704 & ,097 \\
\hline & Benih & -1355055.205 & 1888236.846 & -.050 & -.718 & 478 \\
\hline
\end{tabular}

a. Dependent Variable: Pendapatan

Ket: = jika nilai $\operatorname{sig}<0,05$ (Signifikan)

Nilai Alpa $<0,05$ berpengaruh secara nyata

Hasil dan Pembahasan Analisis Persamaan Regresi linear Berganda

$\mathrm{Y}=303.717,802+265.426,632\left(\mathrm{x}_{1}\right)-108.609,592\left(\mathrm{x}_{2}\right)-1.423\left(\mathrm{x}_{3}\right)-1.355 .055,205$ $\left(\mathrm{x}_{4}\right)$ 
Pada tabel coefficients model 1 terdapat coefficients regresi $\mathrm{X}_{1}$ (luas lahan) koefisien regresi sebesar 265.426,632 dan Nilai sig pada luas lahan $=0,00$. Maka dapat disimpulkan bahwa variabel $\mathrm{X}_{1}$ (luas lahan) berpengaruh terhadap nilai $\mathrm{Y}$ (pendapatan).Karena nilai sig $<0.05$, maka luas lahan berpengaruh terhadap pendapan petani.

Terlihat pada kolom coefficients model 1 terdapat coefficients regresi $\mathrm{X}_{2}$ sebesar $-108.609,592$ dan nilai $\operatorname{sig}=0,775$ pada jumlah tenaga kerja. Maka dapat disimpulkan bahwa variabel $\mathrm{X}_{2}$ (jumlah tenaga kerja) tidak berpengaruh terhadap nilai Y (pendapatan).Karena nilai sig nilai sig> 0,05. Maka jumlah tenaga kerja tidak berpengaruh terhadap pendapatan petani.
Terlihat pada kolom coeffisients model 1 terdapat coefficients regresi $X_{3}$ (biaya produksi) sebesar - 1.423 dan Nilai sig pada biaya produksi $=0,097$. Maka dapat disimpulkan bahwa variabel $\mathrm{X}_{3}$ (biaya produksi) tidak berpengaruh terhadap Y (pendapatan).Karena nilai sig > 0,05, maka biaya produksi tidak berpengaruh terhadap pendapan petani.

Terlihat pada kolom coeffisients model 1 terdapat coefficients regresi $\mathrm{X}_{4}$ (bibit) sebesar -1.355.055,205 dan Nilai sig pada bibit bersertifikat $=0,478$. Maka dapat disimpulkan bahwa variabel $\mathrm{X}_{4}$ (bibit) tidak memiliki pengaruh terhadap nilai Y (pendapatan).Karena nilai sig > 0,05 ,

Tabel 3. Deskripsi Modal Summary Faktor-Faktor Yang Mempengaruhi Pendapatan Petani Padi

\section{Model Summary}

\begin{tabular}{llll}
\hline Model & $\mathrm{R}$ & R Square & Adjusted R Square \\
\hline 1 &, $926^{\mathrm{a}}$ &, 857 &, 841 \\
\hline a. & Predictors: (Constant), Benih, Biaya Produksi, Jumlah Tenaga Kerja, Luas Laha
\end{tabular}

Tabel 3. menunjukkan bahwa secara

Uji ini digunakan untuk mengetahui bersama-sama variabel $\mathrm{R}$ Square apakah variabel independen berpengaruh sebesar 0,857 atau $(\mathrm{X} 1, \mathrm{X} 2, \mathrm{X} 3, \mathrm{X} 4)$ secara bersamaan $85,7 \%$ selebihnya $14,3 \%$ pengaruh dari variabel yang tidak diamati berpengaruh secara segnifikan terhadap dalam penelitian ini seperti harga dan kualitas. variabel dependen. Atau untuk mengetahui apakah model regresi dapat digunakan untuk memprediksi variabel dependen atau 
tidak. Segnifikan berarti hubungan yang terjadi dapat berlaku untuk populasi dapat digeneralisasikan, dari kasus ini populasinya adalah 412 petani sehingga yang menjadi sampel dalam penelitian ini $10 \%$ dari populasi yaitu 41 sampel.

\section{Pembahasan Faktor-Faktor Yang} Mempengaruhi Pendapatan Petani Padi di Kelurahan Pekkabata Kecamatan Duampanua Kabupaten Pinrang

a. Pengaruh Luas Lahan Terhadap Pendapatan Petani Padi

Berdasarkan hasil olah data yang dilakukan, didapatkan koefisien $\mathrm{X}_{1}$ sebesar 265.426,632, yang berarti setiap penambahan luas lahan sebesar 1 are, maka akan terjadi kenaikan pendapatan petani padi sebesar Rp. 265.426,632. Hal ini menunjukkan bahwa luas lahan mempunyai pengaruh terhadap pendapatan petani padi di Kelurahan Pekkabata Kecamatan Duampanua Kabupaten Pinrang.

Lahan merupakan salah satu produksi pertanian dan pada penelitian ini khususnya di Kelurahan Pekkabata memperlihatkan, bahwa luas lahan mempengaruhi pendapatan petani padi. Peneliti menemui fenomena ini pada saat penelitian di Kelurahan Pekkabata Kecamatan Duampanua Kabupaten Pinrang yaitu ketika luas lahan yang digunakan sedikit maka produksi petani akan sedikit sehingga akan berpengaruh pada pendapatan, dan sebaliknya. Pada lokasi penelitian daerah persawahan di Kelurahan Pekkabata juga masih sangat mendukung mulai dari system irigasinya, sehingga itulah luas lahan sangat menentukan pendapatan petani padi, semakin luas lahannya maka semakin banyak pula hasil yang diproduksi.

Hasil penelitian ini sama dengan kesimpulan penelitian yang dilakukan oleh Isyanto (2012) dengan judul Faktor-faktor yang berpengaruh terhadap produksi pada usahatani padi di Kabupaten Ciamis yang memberi kesimpulan bahwa lahan berpengaruh signifikan terhadap produksi padi.

Penelitian ini sesuai dengan penelitian Phahlevi (2013) menemukan bahwa luas lahan, harga jual padi dan jumlah produksi berpengaruh signifikan terhadap pendapatan petani padi sawah di Kota Padang Panjang.

b. Pengaruh Jumlah Tenaga Kerja Terhadap Pendapatan Petani Padi

Berdasarkan hasil olah data yang dilakukan, didapatkan koefisien $\mathrm{X}_{2}$ sebesar 
- 108.609,592 yang berarti setiap penambahan tenaga kerja sebanyak 1 orang, maka pendapatan petani akan berkurang sebesar Rp.108.609,592. Hal ini menunjukkan bahwa tenaga kerja tidak berpengaruh terhadap pendapatan petani padi di Kelurahan Pekkabata Kecamatan Duampanua Kabupaten Pinrang.

Tenaga kerja yang dimaksud dalam penelitian ini adalah jumlah tenaga kerja/buruh tani yang digunakan oleh responden untuk mengelola padi dengan satuan hitung orang dalam sekali panen.Tenaga kerja merupakan faktor produksi yang penting dalam pertanian dan pada penelitian ini khususnya di Kelurahan Pekkabata memperlihatkan, bahwa jumlah tenaga kerja mempengaruhi pendapatan petani padi. Peneliti menemui fenomena ini pada saat penelitian di di Kelurahan Pekkabata, yaitu ketika jumlah tenaga kerja yang digunakan banyak maka petani akan mengeluarkan banyak biaya untuk membayar tenaga kerja. Sehingga ketika petani mengeluarkan banyak biaya, maka pendapatannya akan berkurang. maka ketika petani menambah tenaga kerjanya maka itu akan membuat pendapatannya menjadi berkurang.

Hasil penelitian ini tidak sama dengan kesimpulan penelitian oleh Saleh
(2012) dengan judul Faktor yang Mempengaruhi Pendapatan Petani Tebu di Desa Gunung Anyar Kecamatan Tapen Kabupaten Bondowoso yang memberi kesimpulan bahwa jumlah tenaga kerja berpengaruh positif dan tidak signifikan terhadap pendapatan petani tebu.

Penelitian ini tidak sesuai dengan penelitian Abas (2016) yang menyatakan bahwa tenaga kerja sangat berpengaruh positif terhadap pendapatan dikarenakan dalam kegiatan usahatani sama-sama mengurangi dan meningkatkan pendapatn petani baik tenaga kerja sewa maupun tenaga kerja keluarga sehingga dalam berusahatani dilakukan dengan sunggusunggu sehingga meningkatkan produksi dan pendapatan.

c. Pengaruh Biaya Produksi Terhadap Pendapatan Petani Padi

Biaya Produksi $\left(\mathrm{X}_{3}\right)$ terdapat coefficients regresi $X_{3}$ (biaya produksi) sebesar - 1.423 artinya setiap penambahan biaya produksi sebanyak - 1.423 maka itu akan membuat pendapatan petani padi berkurang sebesar Rp. 1.423. Artinya jika petani menambah biaya produksinya itu akan membuat pendapatan menjadi berkurang. Maka dapat disimpulkan bahwa variabel $\mathrm{X}_{3}$ (biaya produksi) tidak berpengaruh signifikan terhadap 
pendapatan petani karena memiliki nilai $\operatorname{sig}=0,097$.

Biaya produksi adalah semua biaya yang dikeluarkan oleh responden untuk mengelola padi yang dihitung dengan satuan rupiah dalam sekali panen. Pada penelitian ini khususnya di Kelurahan Pekkabata memperlihatkan, bahwa biaya produksi mempengaruhi pendapatan petani padi. Peneliti menemui fenomena ini pada saat penelitian di Kelurahan Pekkabata Kecamatan Duampanua Kabupaten Pinrang yaitu ketika biaya produksi yang digunakan sedikit maka akan meningkatkan pendapatan. Karena ditekannya biaya produksi itu akan membuat pendapatan yang diterima oleh petani meningkat.

Penelitian ini sesuai dengan penelitian Aprilia ( 2019 ) menganalisis tentang pengaruh biaya produksi dan harga jual terhadap pendapatan petani menurut perspektif ekonomi Islam ( studi pada petani jagung Desa Komering Putin Kecamatan Gunung Sugih Kabupaten Lampung tengah ) dengan hasil penelitian menyatakan bahwa biaya produksi dan harga jual berpengaruh signifikan terhadap pendapatan.

Hasil penelitian ini sama dengan kesimpulan penelitian oleh Lumintang
(2012) dengan judul Analisis Pendapatan Petani Padi di Desa Teep, Kecamatan Langowan Timur yang memberi kesimpulan bahwa biaya produksi berpengaruh positif terhadap pendapatan petani dalam pengelolaan usaha tani.

d. Pengaruh Bibit Terhadap Pendapatan Petani Padi

Bibit $\left(\mathrm{X}_{4}\right)$ terdapat coefficients regresi $\mathrm{X}_{4}$ (bibit bersertifikat) sebesar 1.355.055,205 artinya setiap penggunaan bibit 1.355.055,205 maka akan membuat pendapatan petani berkurang sebesar Rp.1.355.055,205. Maka dapat disimpulkan bahwa variabel $\mathrm{X}_{4}$ (bibit) tidak berpengaruh terhadap pendapatan petani karena memiliki nilai sig 0,478 .

Benih bersertifikat adalah benih yang terjamin mutunya dan juga bebas dari bibit penyakit. Pada penelitian ini khususnya di Kelurahan Pekkabata memperlihatkan, bahwa bibit tidak mempengaruhi pendapatan petani padi. Peneliti menemui fenomena ini pada saat penelitian dii Kelurahan Pekkabata Kecamatan Duampanua Kabupaten Pinrang yaitu petani masih belum terlalu memperhatikan soal bibit, karena beberapa petani ketika memilih bibit untuk dia tanam, itu hanya berdasarkan bibit yang sering digunakan. 
Hasil penelitian ini sama dengan Maryono (2008) dalam penelitiannya yang berjudul Analisis Efisiensi Teknis Dan Pendapatan Usahatani Padi Program Benih Bersertifikat: Pendekatan Stochastic Production Frontier (Studi Kasus Di Desa Pasirtalaga, Kecamatan Telagasari, Kabupaten Karawang) menunjukkan bahwa Program benih bersertifikat akan menghasilkan produksi yang optimal apabila didukung dengan teknologi yang menyertainya. Namun dalam pelaksanaannya, teknologi tersebut tidak diaplikasikan oleh petani sehingga produksi padi tidak optimal. Pelaksanaan program benih bersertifikat justru berdampak pada penurunan efisiensi teknis petani pr ogram secara signifikan dibandingkan pada saat sebelum program. Program benih bersertifikat menyebabkan perubahan penggunaan input dan penghematan biaya usahatani sehingga berdampak positif terhadap penurunan biaya riil petani. Namun demikian, penurunan biaya diikuti dengan penurunan produksi yang lebih besar sehingga pendapatan riil petani mengalami penurunan dibandingkan sebelum program

Model summary terlihat $\mathrm{R}$ square sebesar 0,874 hasil kuadrat dari koefisien maka semakin tinggi $\mathrm{R}$ square yang disesuaikan akan semakin baik model regresi dan sebaliknya jika $\mathrm{R}$ square semakin rendah maka tidak berpengaruh terhadap variabel terikat karena variabel tersebut menunjukkan bahwa variabel terikat lebih besar dari variabel bebas. Hal tersebut menjelaskan bahwa variabel bebas (independen), yaitu luas lahan, tenaga kerja dan biaya produksi telah menjelaskan pengaruhnya terhadap variabel terikat dengan (dependen) sebesar 93,1\% dan dalam penelitian ini mempengaruhi pendapatan petani padi di Kelurahan Pekkabata Kecamatan Duampanua Kabupaten Pinrang.

\section{KESIMPULAN DAN SARAN}

Berdasarkan pada uraian bab ini menyajikan hasil penelitian dan pembahasan maka dapat disimpulkan sebagai berikut faktor-faktor yang mempengaruhi pendapatan petani padi di Kelurahan Pekkabata Kecamatan Duampanua Kabupaten Pinrang yaitu luas lahan, jumlah tenaga kerja,biaya produksi dan bibit. Faktor yang berpengaruh signifikan terhadap pendapatan petani padi di Kelurahan Pekkabata Kecamatan Duampanua Kabupaten Pinrang yaitu (X1) luas lahan.

\section{DAFTAR PUSTAKA}

Isyanto, Agus Yuniawan. 2012. FaktorFaktor yang Berpengaruh Terhadap 
Produksi pada Usahatani Padi di Kabupaten Ciamis.

Kasmadi dan Suriah.2013 hal 66.Teknik simple random sampling.

Lumintang, Fatmawati M. 2012. Analisis Pendapatan Petani Padi di Desa Teep Langowan Timur.

Maryono (2008) dalam penelitiannya yang berjudul Analisis Efisiensi Teknis Dan Pendapatan Usahatani Padi Program Benih Bersertifikat: Pendekatan Stochastic Production Frontier (Studi Kasus Di Desa Pasirtalaga, Kecamatan Telagasari, Kabupaten Karawang).

Mia Aprilia ( 2019 ) menganalisis tentang pengaruh biaya produksi dan harga jual terhadap pendapatan petani menurut perspektif ekonomi Islam (studi pada petani jagung Desa Komering Putin Kecamatan Gunung Sugih Kabupaten Lampung tengah )

Rico Phahlevi (2013) menganalisis tentang faktor-faktor yang mempengaruhi pendapatan petani padi sawah di Kota Padang Panjang

Roswati Abas. 2016. Faktor-faktor yang mempengaruhi pendapatan usahatani padi sawah di Kelurahan Mekarsari Kecamatan Tongauna Kabupaten Konawe. Jurusan/Program Studi Agribisnis Fakultas Petanian Universitas Halu Oleo Kendari.

Saleh, Mohammad. 2012. Faktor Yang Mempengaruhi Pendapatan Kelompok Petani Tebu di Desa Gunung Anyar Kecamatan Tapen Kabupaten Bondowoso. Dalam Jurnal ISEI Jember Vol. 2 Nomor 1. Jember: Universitas Jember.

Soekartawi. 2002. Analisis Usaha Tani. UI Press. Jakarta.

Sumber:Badan Pusat Statistik Kabupaten Pinrang 2017 